\title{
Sustained Lung Inflation at Birth via Short Binasal Prong in Very Low Birth Weight Preterm Infants: A Retrospective Study
}

\author{
Mehmet BUYUKTIRYAKI, Hayriye Gozde KANMAZ, Nilufer OKUR, Handan BEZIRGANOGLU, Buse BEKMEZ, Gulsum \\ KADIOGLU SIMSEK, Fuat Emre CANPOLAT, Serife Suna OGUZ, Cuneyt TAYMAN \\ Neonatology, Zekai Tahir Burak Maternity Teaching Hospital, Ankara, Turkey.
}

Background: Sustained lung inflation (SLI) is a lung recruitment maneuver in which peak inspiratory pressure is applied with prolonged inspiration time, thereby moving air into distal airways and providing the time and pressure gradient needed for exchange across the air/fluid interface. It is believed that SLI at birth in preterm infants reduces the need for mechanical ventilation (MV) and improves respiratory outcomes.

Objective: The aim of this study was to compare need for $M V$ in preterm infants at high risk for respiratory distress syndrome (RDS) after prophylactic SLI via short binasal prongs at birth combined with early nasal continuous positive airway pressure (nCPAP) versus nCPAP alone.

Methods: Medical records of infants born at $26^{0 / 7}$ to $29^{6 / 7}$ weeks gestation through 2015 and 2017 were retrospectively assessed. Infants who get sustained inflations at $25 \mathrm{cmH}_{2} \mathrm{O}$ pressure for 15 seconds following delivery via binasal short prongs comprised the study group. Gestational age matched infants who was supported solely with nCPAP ( $6 \mathrm{cmH}_{2} \mathrm{O}$ PEEP) comprised the control group. Early rescue surfactant (200 $\mathrm{mg} / \mathrm{kg}$ poractant alfa) was delivered using the less invasive surfactant administration technique in infants with established RDS.

Infants with major congenital anomalies, perinatal asphyxia, or incomplete medical records in NICU, who underwent rescue SLI application, SLI application or nCPAP via mask and surfactant administration other than LISA (less invasive surfactant administration) method, SLI with different time and pressures rather than stated were excluded from the study.

Results: A total of 590 infants were born at $26^{+0}-29^{+6}$ weeks of gestation in our center during the study period. Patient characteristics' of the groups were similar (Table 1). Need for MV in the first 72 hours of life, was significantly lower in the SLI group when compared with the control group ( 25.7 vs $56.9 \%$, respectively, $\mathrm{p}<0.001$ ). Multiple logistic regression analysis showed that SLI (OR: $0.26,95 \% \mathrm{Cl} 0.13$ to $0.50 ; p<0.001$ ) and 5 min Apgar score over 7 (OR: 0.69, $95 \% \mathrm{Cl} 0.50$ to $0.95 ; p=0.02$ ) reduced the probability of requiring $M V$ in the first 72 hours of life, while preeclampsia (OR: $2.42,95 \% \mathrm{Cl} 1.18$ to $4.96 ; \mathrm{p}=0.01$ ), male gender (OR: $2.01,95 \% \mathrm{Cl} 1.05$ to $3.83 ; \mathrm{p}=0.03$ ), and surfactant requirement (OR: $4.44,95 \% \mathrm{Cl} 2.05$ to $9.59 ; \mathrm{p}<0.001$ ) increased the likelihood of needing $M V$ in the first 72 hours of life. There was no difference between the two groups in surfactant requirement, pneumothorax, death, supplemental oxygen duration and moderate/severe BPD. Other secondary results were significantly better in the SLI group (Table 2). Pneumothorax developed during non-invasive ventilation 4 babies in the $S \mathrm{LI}$ group and in 2 babies in the control group. The incidence of preterm morbidities except BPD were similar in both groups. Mean duration of hospitalization and postmenstrual age at discharge was significantly lower in the SLI group (Table 3).

\begin{tabular}{|c|c|c|c|}
\hline & $\begin{array}{l}\text { SLI Group } \\
(n=113)\end{array}$ & $\begin{array}{c}\text { Control Group } \\
(n=102)\end{array}$ & $\mathbf{p}$ \\
\hline Birth weight $(g)^{*}$ & $1060(865-1250)$ & $1045(855-1230)$ & 0.53 \\
\hline Gestational age (week)* & $28.1(27.3-29.2)$ & $28(27-29.1)$ & 0.50 \\
\hline SGA, n (\%) & $10(8.8)$ & $7(6.9)$ & 0.59 \\
\hline Male gender, n (\%) & $56849.6)$ & $53(52)$ & 0.72 \\
\hline Caesarean delivery, n (\%) & 101 (89.4) & $88(86.3)$ & 0.48 \\
\hline Antenatal steroids, n (\%) & $81(71.7)$ & $75(73.2)$ & 0.76 \\
\hline APGAR score at 5 min* & $8(7-8)$ & $7(6-8)$ & 0.04 \\
\hline CRIB score* & $2(1-4)$ & $2.5(1-5)$ & 0.14 \\
\hline Multiple births, $\mathrm{n}(\%)$ & $22(19.5)$ & $18(17.6)$ & 0.73 \\
\hline Preeclampsia, n (\%) & $23(20.4)$ & $27(26.5)$ & 0.33 \\
\hline Chorioamnionitis, n (\%) & $12(10.6)$ & $11(10.8)$ & 0.96 \\
\hline
\end{tabular}

${ }^{*}$ median, interquartile range (IQR)

CRIB, Clinical risk index for babies; SGA, Small for gestational age (below the 10th centile)

TABLE 2. Clinical outcomes of the groups.

\begin{tabular}{lccc}
\hline & $\begin{array}{c}\text { SLI Group } \\
(\mathbf{n = 1 1 3})\end{array}$ & $\begin{array}{c}\text { Control Group } \\
(\mathbf{n = 1 0 2})\end{array}$ & $\mathbf{p}$ \\
\hline MV within the first 72 h of life, n (\%) & $29(25.7)$ & $58(56.9)$ & $<0.001$ \\
Intubation delivery room, n (\%) & $17(15)$ & $27(26.5)$ & 0.03 \\
Surfactant requirement, $\mathrm{n}(\%)$ & $72(63.7)$ & $72(70.6)$ & 0.28 \\
Duration of MV, days* & $0(0-4.5)$ & $3(0.75-10.5)$ & $<0.001$ \\
Duration of NIV, days* & $6(3-11)$ & $11(4-20.25)$ & 0.002 \\
Duration of suplemental oxygen, days* & $7(3-24)$ & $14(6-23)$ & 0.06 \\
Pneumothorax, $\mathrm{n}(\%)$ & $4(3.5)$ & $2(2)$ & 0.68 \\
BPD, moderate-severe, $\mathrm{n}(\%)$ & $13(11.5)$ & $21(20.6)$ & 0.06 \\
\hline
\end{tabular}

*median, interquartile range (IQR)

BPD, Bronchopulmonary dysplasia; MV, Mechanical Ventilation; NIV, Non-invasive ventilation

TABLE 3. The other preterm morbidities and mortality rates of the groups

\begin{tabular}{lccc}
\hline & $\begin{array}{c}\text { SLI Group } \\
(\mathbf{n = 1 1 3})\end{array}$ & $\begin{array}{c}\text { Control Group } \\
(\mathbf{n = 1 0 2})\end{array}$ & $\mathbf{p}$ \\
\hline hsPDA, n (\%) & $45(39.8)$ & $44(43.1)$ & 0.62 \\
IVH> grade II, n (\%) & $7(6.2)$ & $5(4.9)$ & 0.68 \\
Spontaneous intestinal perforation, n (\%) & $3(2.7)$ & $3(2.9)$ & 1 \\
Necrotising enterocolitis $\geq$ stage II, n (\%) & $1(0.9)$ & $2(2)$ & 0.60 \\
ROP that required laser treatment, $\mathrm{n}(\%)$ & $7(6.2)$ & $12(11.8)$ & 0.15 \\
Duration of hospitalisation, days * & $55(46.5-69.5)$ & $64.5(49.2-84.5)$ & 0.01 \\
Mortality, n (\%) & $16(14.2)$ & $14(13.7)$ & 0.92 \\
\hline
\end{tabular}

IVH, Intraventricular haemorrhage; hsPDA, hemodynamically significant patent ductus arteriosus; ROP, Retinopathy of prematurity

Conclusions: SLI maneuver via short binasal prongs is feasible and when compared to nCPAP alone, prophylactic SLI at birth followed by early nCPAP reduces the need for $M V$ in the first 72 hours of life with no adverse effects in VLBW infants. Larger, randomized controlled trials using binasal prongs and the LISA approach are needed in preterm infants.

\section{References:}

1. Lista G, Cavigioli F, Castoldi F, Zimmermann LJ. Sustained inflation: Prophylactic or rescue maneuver? Semin Fetal Neonatal Med. 2016;21:135-8.

2. Lista G, Fontana P, Castoldi F, Cavigioli F, Dani C. Does sustained lung inflation at birth improve outcome of preterm infants at risk for respiratory distress syndrome? Neonatology. 2011;99:45-50.

3. Jiravisitkul P, Rattanasiri S, Nuntnarumit P. Randomised controlled trial of sustained lung inflation for resuscitation of preterm infants in the delivery room. Resuscitation. 2017;111:68-73. 